\title{
Intraocular Pressure Changes After Intravitreal Bevacizumab Injection Alone or Combination of Bevacizumab and Triamcinolone Acetonide
}

\author{
Nour Yasser Barakat ${ }^{*}$ Yusuf Suleiman, Kahtan Jalloul \\ Ophthalmology Department, Faculty of Medicine of Tishreen University, Lattakia, Syria
}

Email address:

bnour974@gmail.com (N. Y. Barakat)

*Corresponding author

To cite this article:

Nour Yasser Barakat, Yusuf Suleiman, Kahtan Jalloul. Intraocular Pressure Changes After Intravitreal Bevacizumab Injection Alone or Combination of Bevacizumab and Triamcinolone Acetonide. International Journal of Homeopathy \& Natural Medicines.

Vol. 6, No. 2, 2020, pp. 6-14. doi: 10.11648/j.ijhnm.20200602.11

Received: July 31, 2020; Accepted: August 12, 2020; Published: December 11, 2020

\begin{abstract}
Aim: To evaluate intraocular pressure changes after intravitreal injection of Bevacizumab alone or in combination with Triamcinolone Acetonide. Method: Our study included 63 eyes from the ophthalmology department at Tishreen University Hospital who had vascular retinal diseases. The patients were divided into two groups according to the indication of injection. The first group was injected with bevacizumab (B) at a concentration of $2.5 \mathrm{mg} / 0.1 \mathrm{ml}$ and the second group was injected with the combination treatment of Triamcinolone Acetonide at a concentration of $2 \mathrm{mg} / 0.05 \mathrm{ml}$ with bevacizumab $(\mathrm{B}+\mathrm{TA})$ at a concentration of $1.25 \mathrm{mg} / 0.05 \mathrm{ml}$. Intraocular pressure was monitored on the Goldman applanation tonometry and values were recorded as follows: before injection, the second injection day, a week after injection, a month after injection and after three months. Results: The mean values of the intraocular pressure mean increased from the second day of injection in the study groups (B) and (B+TA) and the mean of the IOP values before injection (13.34-13.31 mmHg) respectively, and the IOP values showed the maximum in both groups after a week of the injection $(17.81-17.31 \mathrm{mmHg})$ then began to decrease after a month and three months later to $(17.34-17.06 \mathrm{mmHg})$ and $(17.6-16.75 \mathrm{mmHg})$ mercury respectively, but they remained higher than they were before the injection, and the number of injections had no effect on intraocular pressure. Conclusion: intravitreal injections with both bevacizumab alone or in combination with triamcinolone acetonide resulted in a rise in intraocular pressure, and differences in pressure values were statistically significant within the same group during the studied time periods but were not statistically significant between the two groups, and the number of injections had no effect on intraocular pressure.
\end{abstract}

Keywords: Bevacizumab, Triamcinolone Acetonide, Intraocular Pressure

\section{Introduction}

Vascular eye diseases are the main causes of visual loss and blindness around the world, as diabetic retinopathy, agerelated macular degeneration, and central retinal vein occlusion are the most prevalent of these diseases, [1] and diabetic retinopathy is most important reason for visual loss acquired around the world among working people. [2]

Vascular endothelial proliferation factors (VEGF) play an important role in the mechanism of the occurrence of neovascularization in the context of these diseases, as they contribute to produce macular edema by breaking the retinal blood barrier and increasing vascular permeability as well as being a chemical attraction to leukocytes. [3]

The injection of anti-VEGF inhibitors has been widely used in the treatment of many diseases of the retina and choroid vascular, as well as in improving patient visual acuity suffering of macular edema in the context of diabetic retinopathy and retinal vein occlusion. $[4,5]$

Corticosteroids have been prescribed to treat inflammatory eye diseases since the early 1950s and have been and still are a good treatment option for many eye back diseases due to their anti-inflammatory and inhibitory effect on vascular growth in addition to their effectiveness as an anti-edema. [6] 
Bevacizumab and Triamcinolone acetonide are the most used compound for treating diabetic macular edema due to their high effectiveness and its low cost. [7]

Bevacizumab is a full-length recombinant humanized antiVEGF monoclonal antibody that binds all isoforms of VEGF. A, it is used currently to treat many retinal diseases due to its benefits as a vascular inhibitor and edema [8], it is usually used as an intravitreal injection with a concentration of $(1.25 \mathrm{mg} / 0.05) \mathrm{ml}$ or $(2.5 \mathrm{mg} / 0.1 \mathrm{ml})$ [9], its half-life is about 4.32 days, and has short-life effects which does not exceed 30 days, so, it is necessary to repeat its injections to ensure its effect continuity. [10]

Triamcinolone acetonide (TA) is a corticosteroid that has anti-inflammatory and vascular inhibitory effects, commonly used to treat diabetic macular edema, the primary mechanism of its action within vitreous is unknown, it is used for its ability to inhibit the arachidonic pathway, reduce cytokines production and breaking the retinal blood barrier [11]. After entering into the vitreous it is associated with the vitreous collagen network, and remains within the vitreous cavity for months [12] so, it has prolonged effect.

In spite of the high effectiveness of these compounds and their widespread use, their use may result in several complications and side effects such as: subconjunctival hemorrhage, corneal edema, conjunctival edema, tears and detachment of the retina, lens damage and cataract development, choroid injury, vitreous hemorrhage, increased intraocular pressure and even endophthalmitis. [13]

Currently, the increase of IOP caused by intravitreal injection focused the attention of specialists in this field.

The intraocular pressure may be short-term and expected, and it may reach more than $30 \mathrm{mmHg}$ during the first five minutes of injection, but its spontaneous decomposition occurs within 30-60 minutes due to the expansion of the sclera in progressively with volume of the injection material. $[14,15]$

The elevation of the IOP may be long-term and extend for weeks or months. [16]

The acute rise in IOP causes a decrease in the blood perfusion of the juxtpapillary and optic nerve head, which in turn causes damage to the ganglion cells and results in permanent visual loss if treatment does not effectuated quickly. [17]

Most studies related to this topic have focused on measuring intraocular pressure immediately after injection without following future changes in the intraocular pressure, so, it is important to highlight the monitoring of pressure changes caused by intravitreal injection with these substances for consecutive periods after injection.

\section{Materials and Methods}

\subsection{Design}

Prospective comparative study.

\subsection{Subjects}

The study included 63 of patients eyes from the ophthalmology department at Tishreen University Hospital in Lattakia, Syria, during the period from 1st January 2019 to 1st January 2020 who had vascular retinal diseases: diabetic macula and retinopathy DMR (44 patients), wet age macular degeneration AMD (12 patients), retinal vein occlusion RVO (6 patients), hypertensive retinopathy 5 HR (1 patient). The number of injections ranged between 1 (12 patients), 2 (5 patients), 3 (47 patients).

\subsubsection{Ethical Consideration}

An informed consent and ethical committee clearance were taken for this study.

\subsubsection{Inclusion Criteria}

Patients with vascular retinal diseases (wet-macular degeneration, retinopathy and diabetic stain, central retinal vein occlusion, hypertensive retinopathy).

\subsubsection{Exclusion Criteria}

Patients who had: Glaucoma, patients with IOP values more than $21 \mathrm{mmHg}$, history of elevated IOP or precedents for taking IOP-lowering drugs, any eye inflammation whether in the eye in which it will be injected or in the other eye and will affect the values of IOP, previtrectomy.

\subsection{Investigations}

Globale eye examination was performed for all patients including: (visual acuity, examination of anterior departments on the slit lamp, fundus endoscopy after pupillary expansion with Tropicamide 1\%, macula and optic nerve OCT procedure, intraocular pressure measurement by Goldman applanation tonometry). Patients were divided into two groups according to the indication of injection: the first group (B) was injected with Avastin (bevacizumab) $(2.5 \mathrm{mg} / 0.1 \mathrm{ml}$ ) and the second group (B+TA) was injected with combination of triamcinolone acetonide $(2 \mathrm{mg} / 0.05 \mathrm{ml})$ with bivacizumab $(1.25 \mathrm{mg} / 0.05 \mathrm{ml})$. Patients were divided between the two groups by the ophthalmologist at the clinic, who injected patients. A comprehensive sterilization with povidone $5 \%$ for the skin area was performed, the conjunctiva was anesthetized with povidone 5\% after anesthesia with an anesthetic drop of lidocain $1 \%$, sterile channels were placed and sterile eyelids. Syringe injection was performed with 30 gosh, at $3.5 \mathrm{~mm}$ from the limb in the eyes with the pseudophakic lens and $4 \mathrm{~mm}$ from the limb in the eyes with the phackic lens. Patients were 6 given a (Levoquix) drop two days before injection and for one week after injection. Intraocular pressure (IOP) was measured during the following periods: before the injection, the second day, a week, a month and after three months of injection.

\subsection{Statistical Study}

The statistical study of the research included: a descriptive statistic of sample includes the mean $\pm \mathrm{SD}$ for the quantitative variables, the percentages for the qualitative variables, and an 
inferential statistical statistic that includes: Independent $\mathrm{T}$ student test to study the differences of pressure averages between two independent groups, the Friedman Test to compare the mean pressure at sequential times for one group, Chi-squere test to study the relationships between qualitative variables. Results were statistically significant when p-value $<0.005$, and the IBM SPSS statistics program was adopted to calculate statistical parameters and analyze results.

\section{Results}

The samples of the study included 63 eyes ( 31 males, 32 females) who had retinal vascular diseases from the eye clinic reviewers at Tishreen University Hospital in Latakia, during the period 2019-2020, and who will undergo intravitreal injection for the first time. The patient ages ranged from 20 to 76 years and the mean age was 60 years with Rang $=56$ years.

\subsection{Disease Samples Distribution According to Their Indication for Injection}

Figure 1 showed that about $70 \%$ of study samples who have injection are DMR, 18.7\% suffer from AMD, 9.4\% have RVO and $1.6 \%$ have HR.

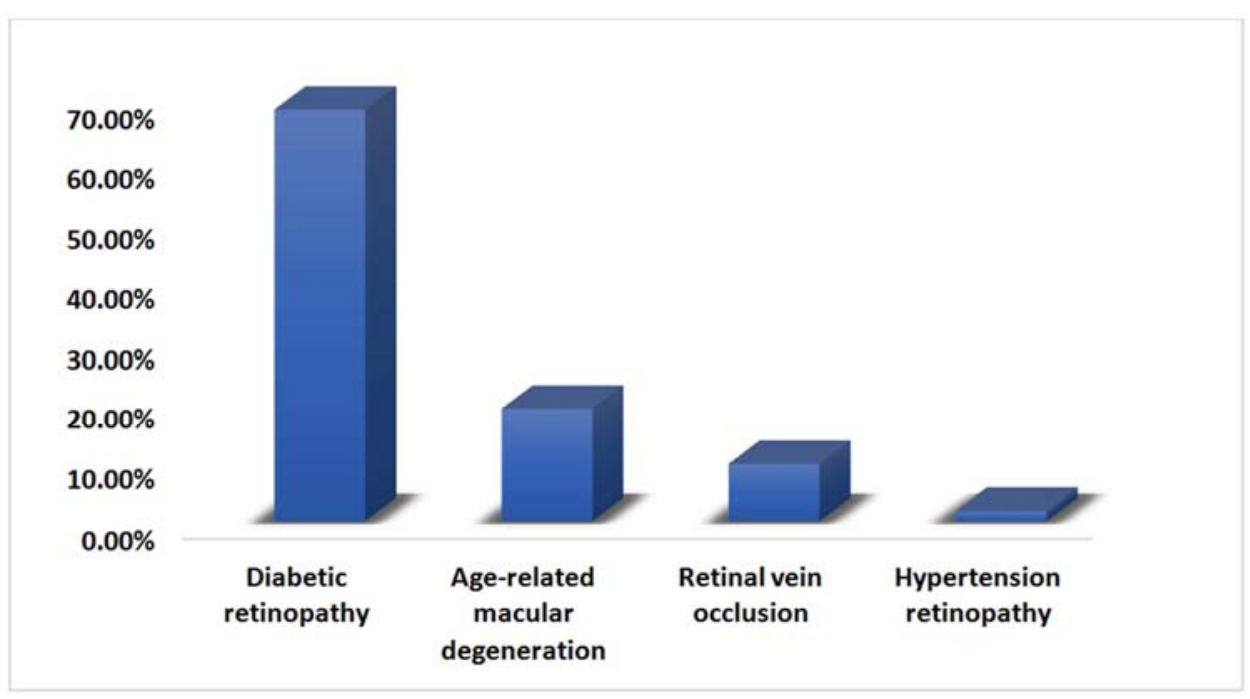

Figure 1. Distribution of 63 eyes according to the indication of injection into two groups.

\subsection{Distribution of Patients According to Ophthalmic and Systemic Precedents}

Table 1 indicates the distribution of patients according to ocular precedents, which included 19 patients who had a history of cataract surgery, while according to systemic precedents: the number of patients who had type I diabetes (2), and who had type II diabetes (45), and who had arterial hypertension (35), patient may have more than one systemic disease

Table 1. Distribution of patients according to ophtalmic and systematic precedents.

\begin{tabular}{lll}
\hline ophthalmic and systemic precedents & Number & Percentage \\
\hline Ophtalmic: & & \\
Cataract surgery & 19 & $29.7 \%$ \\
Systemic: & & \\
Type I of Diabetes & 2 & $3.1 \%$ \\
Type II of Diabetes & 45 & $70.3 \%$ \\
Arterial hypertension & 35 & $54.7 \%$ \\
\hline
\end{tabular}

\subsection{Demographic Changes Differences between the Two Research GROUPS}

Study simple included 63 eyes, male eyes number ranged from 15 eyes in group (B) and 16 eyes in group (B+TA) Mean age in the group (B) ranged from $59.8 \pm 11.7$ years and in group

(B+TA) $62.1 \pm 10.7$ years, number of injections ranged from 1 (12) patients, 2 (5 patients), 3 (47 patients). Most of patients needed 3 injections in both groups, and there were no statistically significant differences between the two groups in terms of sex and age, as shown in Table 2.

Table 2. Demographic differences between the two groups of patients.

\begin{tabular}{llll}
\hline \multirow{2}{*}{$\begin{array}{l}\text { Demographic } \\
\text { differences }\end{array}$} & \multicolumn{2}{l}{ Type of injection } & \multirow{2}{*}{ P-value } \\
\cline { 2 - 3 } & B & B+TA & 1 (N. S) \\
Gender (male) & $15(50 \%)$ & $16(50 \%)$ & $0.4(\mathrm{~N} . \mathrm{S})$ \\
Age & $59.8 \pm 11.7$ & $62.1 \pm 10.7$ & \\
Number of injection & & & \multirow{2}{*}{0.2 (N. S) } \\
1 & $3(12.5 \%)$ & $8(25 \%)$ & \\
2 & $4(12.5 \%)$ & $1(3.1 \%)$ & $23(71.9 \%)$ \\
3 & $24(75 \%)$ & & \\
\hline
\end{tabular}

\subsection{Mean Variations of Intraocular Pressure Values Within Group B}

Table 3. Mean of the intraocular pressure values within group (B).

\begin{tabular}{lll}
\hline Times & Mean of IOP & P-value \\
\hline Pre-injection & $13.34 \pm 1.6$ & \\
Second day after injection & $17.17 \pm 3.1$ & \multirow{2}{*}{0.0001} \\
After week of injection & $17.81 \pm 3.1$ & \\
After month of injection & $17.34 \pm 2.7$ & \\
After 3 month of injection & $17.06 \pm 2.7$ & \\
\hline
\end{tabular}


Table 3, showed an increase in IOP values in group B starting from the second day of injection. The mean pressure values increased from $13.34 \pm 1.6 \mathrm{mmHg}$ before injection to $17.17 \pm 3.1 \mathrm{mmHg}$ on the second day of injection, and reached its maximum after a week of the injection $17.81 \pm 3.1 \mathrm{mmHg}$ and then started to decrease gradually and very slightly, but it was not returned to its pre-injection level. Differences in the average IOP values before injection and after injection were statistically significant in the various follow-up time period $(\mathrm{P}=0.0001)$.

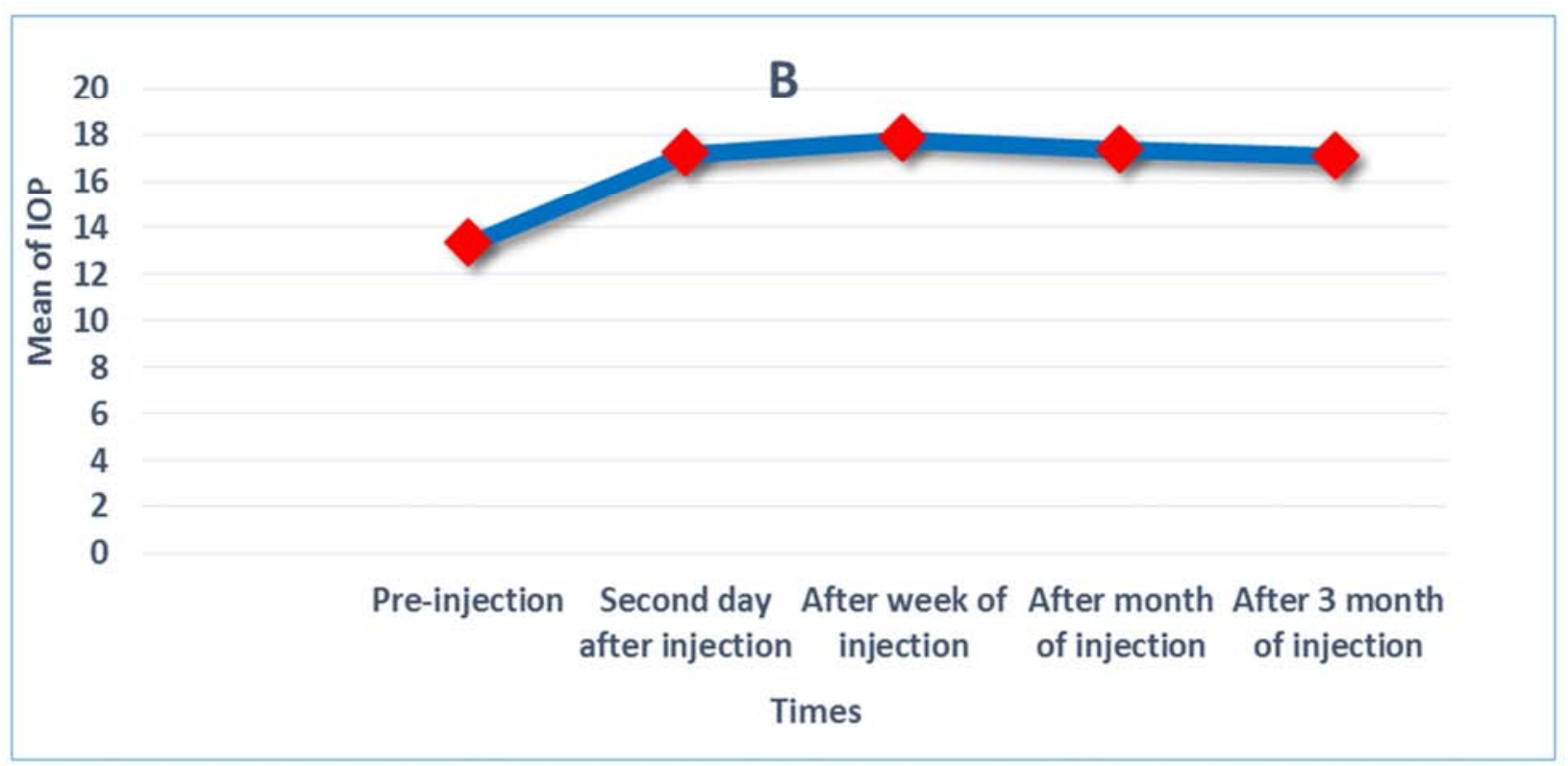

Figure 2. Intraocular pressure mean values of group $B$.

\subsection{Intraocular Pressure Mean Values in Group B+TA}

Table 4 showed that injection of B+TA was accompanied by an increase in the mean IOP values, mean IOP values increased from $(13.31 \pm 1.8) \mathrm{mmHg}$ to $(17.06 \pm 2.5) \mathrm{mmHg}$ on the second day of injection and reached its maximum after a week of injection, where it reached $(17.31 \pm 2.3) \mathrm{mmHg}$, then it started to decrease gradually without returning to its preinjection level. The differences in the mean pressure values before and after the injection were statistically significant.
Table 4. Mean of the intraocular pressure values within group $B+T A$.

\begin{tabular}{lll}
\hline Times & Mean of IOP & P-value \\
\hline Pre-injection & $13.31 \pm 1.8$ & \\
Second day after injection & $17.06 \pm 2.5$ & \\
After week of injection & $17.31 \pm 2.3$ & 0.0001 \\
After month of injection & $17.06 \pm 2.6$ & \\
After 3 month of injection & $16.75 \pm 2.2$ & \\
\hline
\end{tabular}

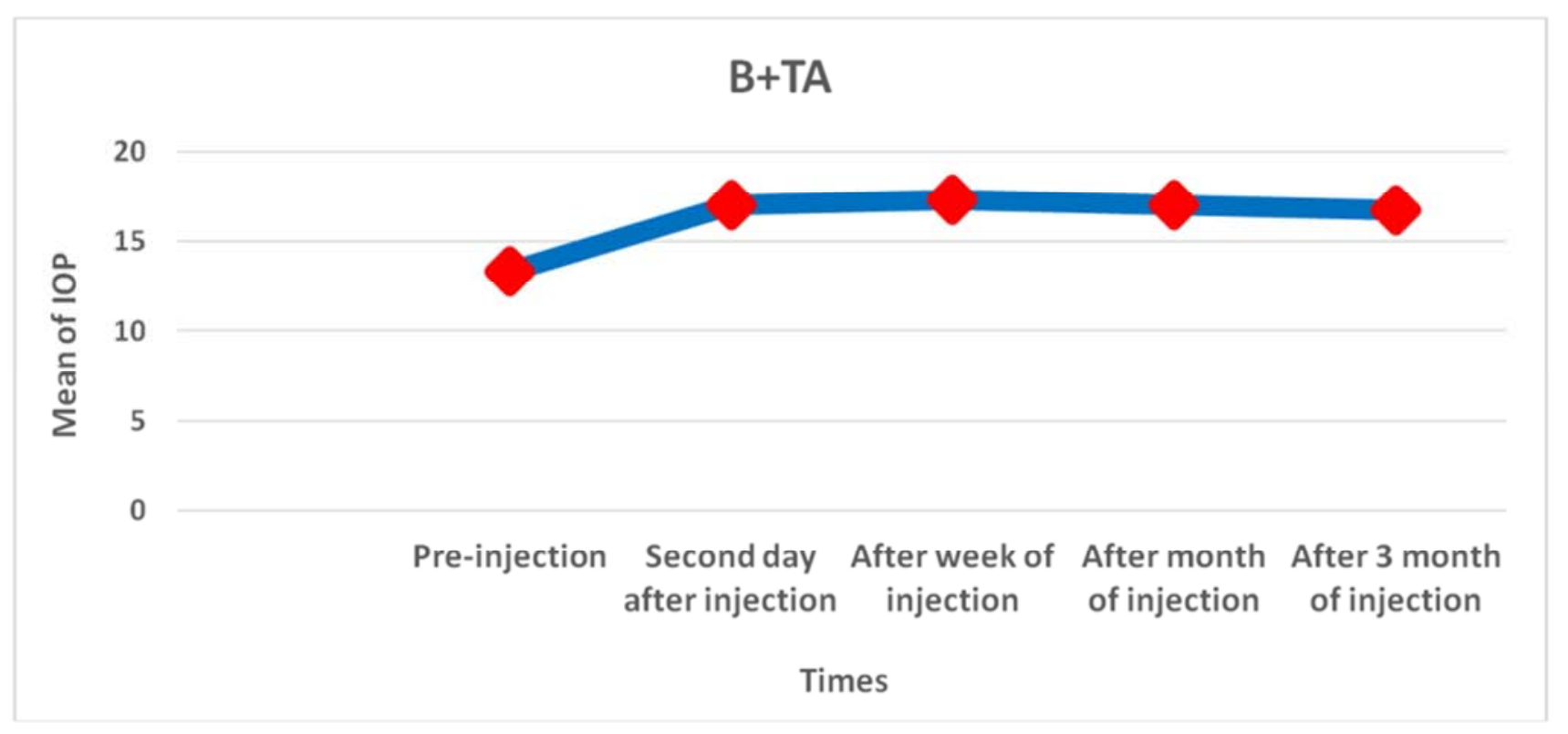

Figure 3. Intraocular pressure mean values of group B + TA group. 


\subsection{Comparison of Intraocular Pressure Changes Between Group $B$ and $B+T A$}

The results of Table 5 indicate that the intravitreal injection with $\mathrm{B}$ alone or in combination with TA was associated with an increase the values of IOP from the second day of injection, and the differences in mean pressure values before and after the injection were statistically significant within the same group ( $p$-value $=0.0001$ ). Mean value of IOP reached its maximum in both groups a week after injection, (17.31-17.81 $\mathrm{mmHg}$ ) respectively, and no significant differences were observed between the two study groups.
Table 5. Comparing intraocular pressure changes between group of patients (B) and $(B+T A)$

\begin{tabular}{llll}
\hline \multirow{2}{*}{ Times } & \multicolumn{2}{l}{ Type of injection } & \multirow{2}{*}{ p-value } \\
\cline { 2 - 3 } & B & B+TA & \\
\hline Pre-injection & $13.34 \pm 1.6$ & $13.31 \pm 1.8$ & 0.9 (N. S) \\
Second day after injection & $17.17 \pm 3.1$ & $17.06 \pm 2.5$ & 0.8 (N. S) \\
After week of injection & $17.81 \pm 3.1$ & $17.31 \pm 2.3$ & 0.4 (N. S) \\
After month of injection & $17.34 \pm 2.7$ & $17.06 \pm 2.6$ & 0.6 (N. S) \\
After 3 month of injection & $17.06 \pm 2.7$ & $16.75 \pm 2.2$ & 0.6 (N. S) \\
\hline
\end{tabular}

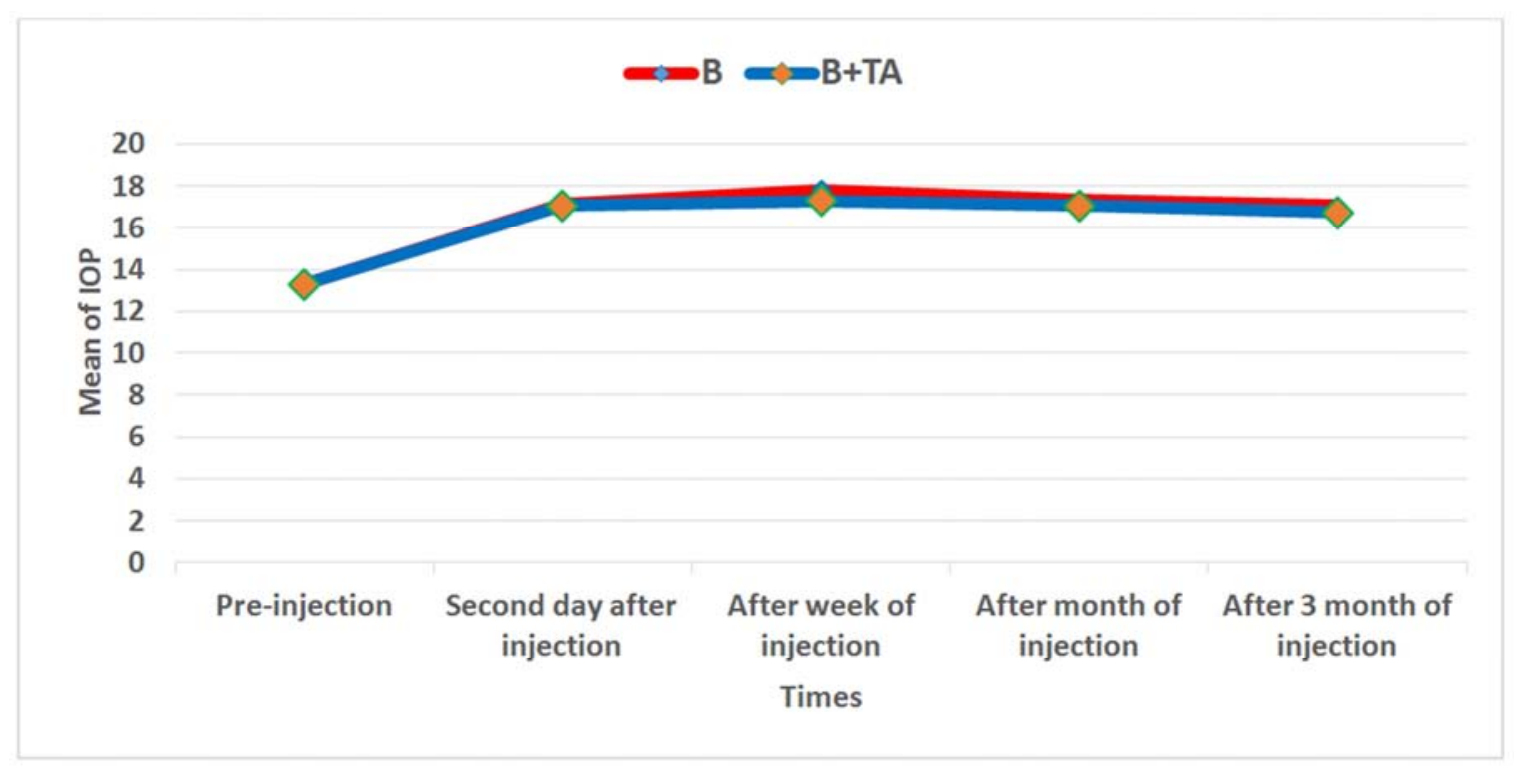

Figure 4. Comparison of the intraocular pressure changes mean values between the two patient groups.

\section{7. The Effect of the Number of Injections with B or B+TA on the Intraocular Pressure Changes}

The results showed that no changes occurred in the mean values of the IOP with the increase in the number of injections in the two study groups, Table 6 .

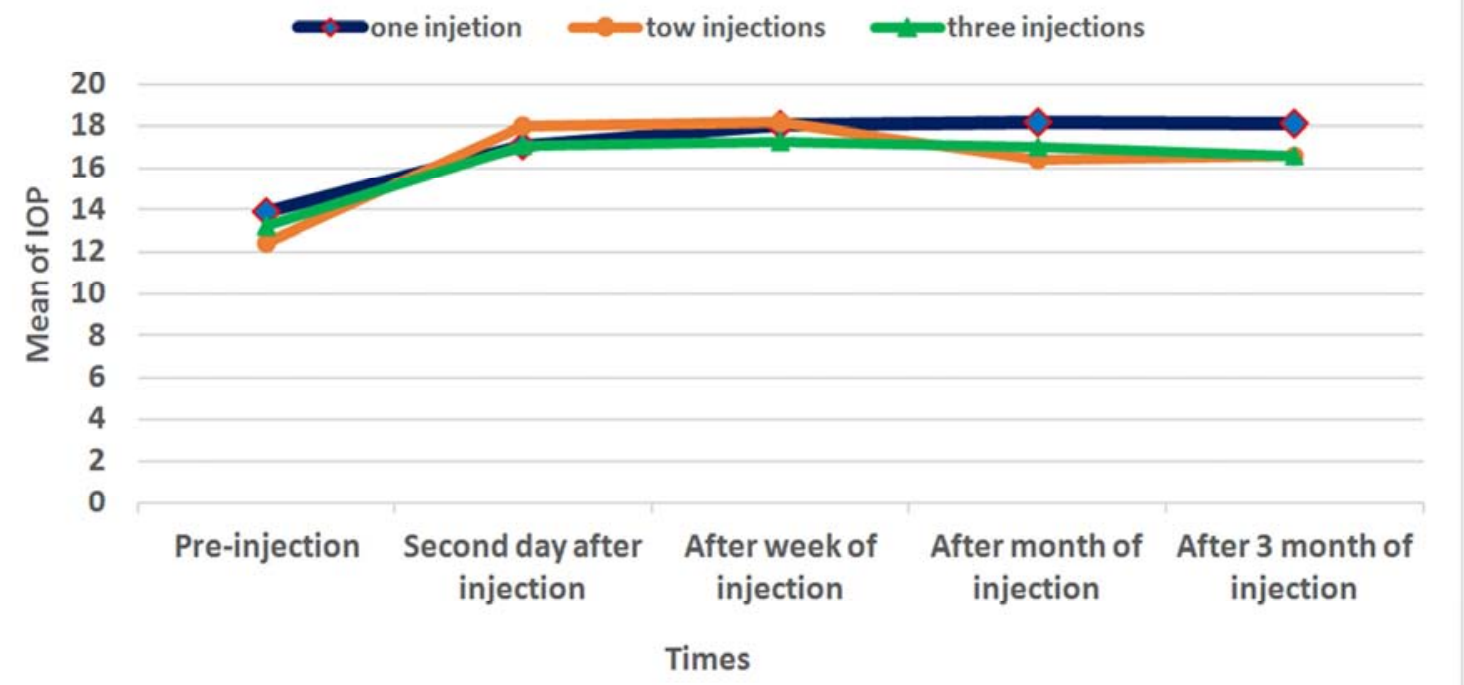

Figure 5. The relationship between the number of injections and pressure changes between the two groups of patients. 
Table 6. Pressure mean values according to the number of syringes for both groups.

\begin{tabular}{|c|c|c|c|c|}
\hline \multirow{2}{*}{ Times } & \multicolumn{3}{|c|}{ Number of injection } & \multirow{2}{*}{ p-value } \\
\hline & 1 & 2 & 3 & \\
\hline Pre-injection & $13.9 \pm 2.02$ & $12.4 \pm 0.8$ & $13.2 \pm 1.7$ & 0.2 (N. S) \\
\hline Second day after injection & $17.1 \pm 2.4$ & $18 \pm 2.4$ & $17.01 \pm 2.9$ & 0.7 (N. S) \\
\hline After week of injection & $18.08 \pm 2.3$ & $18.2 \pm 2.1$ & $17.3 \pm 2.9$ & 0.6 (N. S) \\
\hline After month of injection & $18.2 \pm 2.5$ & $16.4 \pm 3.1$ & $17.02 \pm 2.4$ & 0.2 (N. S) \\
\hline After 3 month of injection & $18.1 \pm 2.2$ & $16.6 \pm 3.3$ & $16.6 \pm 2.4$ & 0.1 (N. S) \\
\hline
\end{tabular}

An increase in IOP values over the normal limits for 6 patients ( 3 cases by $9.4 \%$ in each group) where occurred and 4 patients needed treatment with one local anti-glaucoma medication (Timolol maleate) because of their IOP $<22$ $\mathrm{mmHg}$. Two patients needed combination therapy with antiglaucoma medication (Dorzolamide hcl+Timolol maleate). Patients did not need permanent treatment with antiglaucoma medication, when duration of treatment ranged between two weeks to a month. No complications in the injection group (B) were noticed, while in the group of combination therapy (B+TA), cataract develops in 5 cases $(15.6 \%)$, whereas any cases of hemorrhage, endophtalmitis, or retinal detachment were not noticed.

\section{Discussion}

Through the research conducted which aimed to study the changes of IOP values when injected with bevacizumab alone or in combination with triamcinolone acetonide, we have concluded:

An increase of the mean values of IOP in both group B and group $\mathrm{B}+\mathrm{TA}$ after injection and with a statistical significance in all observation periods compared to its value before injection, where the mean pressure values before injection in group B (13.34 \pm 1.6$) \mathrm{mmHg}$ and rised in the second day to $(17.17 \pm 3.1) \mathrm{mmHg}$ and continued to rise during the followup period to reach its maximum after a week of injection $(17.81 \pm 3.1) \mathrm{mmHg}$, with an increasing rate of $(4.47 \mathrm{mmHg})$. While IOP average values in group (B+TA) was (13.31 1.8$)$ $\mathrm{mmHg}$ before injection, and its value increased on the second day of injection to $(17.06 \pm 2.5) \mathrm{mmHg}$, to reach its maximum after a week of injection $(17.31 \pm 2.3) \mathrm{mmHg}$, with an increasing rate of $(4 \mathrm{mmHg})$.

There was a slight decrease in IOP values in both groups after the third month of injection, but its value remained higher than before injection.

Our results in terms of high IOP values after injection with bevacizumab were consistent with many researchers' results. In a study of Pershing et al, were conducted at Stanford University and in the Mayo Center to assessing the changes of IOP after antiVEGF intravitreal injection within 4 years, they found an increase in IOP values after injection with bevacizumab which is in consistent with our study. But the increase in the Pershing et al study was late, and happened after 15 months of treatment and after taking 10 injections. The reason of this increase may be due to a cumulative effect of the injection, while in our study, the increase occurred from the second day of the injection and it continued throughout the 3-month follow-up period. [18]
In a study of Sulman Jaffar et al, which aimed to assess the long-term effect onIOP after $(6,12)$ months of intravitreal bevacizumab injection, they found an increase in IOP average values after 6 months of bevacizumab injection and with a statistical significance compared with Its value before injection. This corresponds to our results, but there was no increase of IOP average value of after 12 months. [19]

Mehmet Ozgur et al study, which lasted 5 years (20122017), indicated a significant increase in of IOP values after bevacizumab injection, but their follow-up period was longer than ours. [20]

Behrooz et al, study that conducted in Iran to assess changes in intraocular pressure values and its value one day after bevacizumab injection, indicated that there was no increase in IOP values after 24 hours of injection compared to its value before injection. This is in contrasts with our results, where pressure increased 24 hours after the injection (the second day) and with a statistical significance compared to its value before the injection. They follow-up the IOP 24 houer injection compared to our study which lasted 3 months. [21]

In a study of Jong Lee et al., conducted in Korea at the Eulji Medical Center to assess the effect of intravitreal antiVEGF injection on intraocular pressure (IOP) during periods: (after 30 minutes, a day and a week after the injection), They found an increase in the IOP values immediately after the injection, which was $(16.66 \pm 3.50)$ $\mathrm{mmHg}$ before the injection and an increased significantly after the injection to $(43.81 \pm 9.69) \mathrm{mmHg}$ and then decreased after 30 minutes of injection to $(17.57 \pm 4.44) \mathrm{mmHg}$, and it continued to decrease even after a week of injection $(15.90 \pm 3.63) \mathrm{mmHg}$. This is inconsistent with the results of our study. [4]

Yogish et al, study conducted in India to assess the changes in IOP after intravitral bevacizumab injection, showed as well an increase in IOP values 4 hours after injection compared to pre-injection but there was no significant increase in its values after 2 and 6 weeks of injection compared to the pre-injection. This is in contrasts with our results. [22]

In a study of Ashiyana et al, which conducted in Chicago, and its similar to our study which included 131 patients (76 have AMD) and (55 have DME), IOP was measured during the months $(0-6,6-12,12-18,18-24$ and $>24)$ after the injection of antiVEGF and compared the results with the values of IOP before injection, they found that no significant increase in IOP occurred after injection during the follow-up period, and this is inconsistent with our study. [23]

Mahmood et al study conducted in Pakistan, and Sibel et al 
study conducted in Turkey, showed no increase in IOP values in diabetic macular edema patients treated with bevacizumab, and this is inconsistent with our study [24, 25].

There are several hypotheses related to the pathophysiology of the sustained rise of IOP after intravitreal injection of antiVEGF, including: inflammatory response, direct toxic effect of antiVEGF factors on the trabecular meshwork, damage of the trabecular meshwork due to injection of a large amount of fluid [18] or it may be the result of occlusion of the trabecular meshwork or even the schlemm channel with large particles of matter where the molecular weight is $149 \mathrm{KD}$ [26]. The damage of the flow through the ciliary body with silicon proteins and molecules that may be present within syringes used for intravitreal injection [27] and other hypotheses related to the total number of injections, the interval between injections, eyes with a known history of a glaucoma or an increase in IOP, the axial length of the eye and the depth of anterior chamber [28].

The changes of IOP average values after injection of (B+TA) were similar to changes resulted of (B) injection alone with a statistical significant compared to its values before injection.

These results were consistent with the results of Ahmet et al study, which showed an increase in IOP values after combination treatment (B+TA) a week after injection. [29]

In a study of Yong et al conducted in Korea on 259 patients and aimed to compare the effect of injections with bevacizumab alone or in combination with triamcinolone acetonide on changes in IOP values during the following time periods: before injection, after 1 week, 1 month, 2 months 3 months, 6 months, one year after injection, they found a significant increase in IOP average values in the combined treatment group one month after the injection and reached its maximum after 3 months of injection compared to its value before injection with a statistically significant difference $(\mathrm{P}=0.005, \mathrm{P}=0.006)$, respectively, these results are consistent with our results, where IOP values increased significantly in all follow-up periods compared to its value before injection [30].

The results of Sameh et al conducted in Egypt and aimed to evaluate the efficacy and safety of intravitreal injections of bevacizumab, triamcinolone acetonide, or combined therapy (bevacizumab+triamcinolone acetonide) indicated that a significant rise in IOP values occurred during follow-up months 1, 3, 6, compared to the initial IOP values within the (IVB+IVTA) combination treatment group. This corresponds to the results of our study. [31]

These results support the finding of Golakiya et al there were a significant increase in IOP and reached more than 42 $\mathrm{mmHg}$ after the combined treatment (bevacizumab+triamcinolone acetonide) in the context of macular edema of one patient and needed surgery and recovery occurred after a month, while in our study only 6 patients of 63 patients needed local anti-glaucoma medication only without the any surgery. [32]

Clark has indicated that the reason for the high IOP due to the steroid injection is the increased aqueous humor outflow resistance through trabecular meshwork and is associated with morphologic changes in the trabecular meshwork, There are three possible and synergistic mechanisms to increase the resistance of aqueous humor outflow that leads to the high intraocular pressure which are: structural changes In the trabecular meshwork, Inhibition of phagocytosis in the cells of the trabecular meshwork, mechanical blockage of the trabecular meshwork with steroids [33].

In Valerie et al, study conducted in Washington aimed to evaluate intraocular pressure in treated eyes with $1.25 \mathrm{mg}$ of bevacizumab in combination with $1 \mathrm{mg}$ of triamcinolone acetonide, they found no significant rise in IOP after combination injection during the follow-up period that continued 6 months and this differs from the results of our study [35].

In a study of Sever et al, conducted in Turkey, no significant increase was observed in IOP mean values compared to the primary IOP within the injection group either by bevacizumab alone or in combination with triamcinolone acetonide during the follow-up period $(\mathrm{P}>$ $0.05)$ and this contrasts with our study. The difference between our results and the results of Valerie et al, and Sever et al, may be due to the use of a low dose of triamcinolone acetonide (1 mg), while we used $(2 \mathrm{mg})$ in our study. [34, 35]

Our results indicated that there were no statistically significant differences in IOP mean values between the two treatment groups and this result was consistent with the results of the Sever et al, and with the results of a study Yong et al., which compared the average IOP values between group (B) and group (B+TA). [34, 30]

Our results showed that there were no effects of number of injections on IOP values within the two treatment groups. The differences in the average pressure values in patients who received one, two or three injections were statistically insignificant $(\mathrm{P}=0.2)$.

Our results are in consistent with the results of Tze et al, which conducted in Taiwan and included 209 eyes of 173 patients who received at least 3 intravitreal injections of Bevacizumab in the context of age macular degeneration, and found that no significant changes occurred In the IOP (P: 0.41). [36]

Our results coincide as well with the results of Ashiyana et al, Falkenstein et al, and Yogish et al, who found that the average IOP values were not affected by the number of injections that patient received, whether by bevacizumab alone or in combination with triamcinolone acetonide $[23,37$, 22].

While our results does not support the results of Yandan Zhou et al, which was conducted in China, where IOP values were monitored after antiVEGF injection during the months: $6,12,24$, and they found that the frequency of intravitreal injection causes an increase in the IOP. [38]

The results of Mehmet Ozgur et al, also does not accord our results, which showed a relationship between the number of injections and the increase of the IOP. [20] 


\section{Conclusion}

Our study founded that an increase in IOP average values in group $\mathrm{B}$ and group $\mathrm{B}+\mathrm{TA}$, with a statistical significance compared to its value before injection in all follow-up periods. IOP average values in both groups reached their maximum after a week of injection and then started to decrease, but its value remained higher than it was before the injection. We did not find a statistical difference of IOP mean values between group B and group B+TA, as well as we did not notice an effect of the number of injections on the average values of IOP in both groups. We recommend monitoring intraocular pressure after intravitreal injection, whether it is injected with bevacizumab alone or in combination with triamcinolone acetonide for successive periods.

\section{Acknowledgements}

We gratefully acknowledge Dr. Mona Barakat and Dr. Sawsan Suleiman for assistance in writing the manuscript, as well as we would like to thank Elissar Hejazia for conducting the statical analysis.

\section{References}

[1] Brand CS. Management of retinal vascular diseases: A patient-centric approach. Eye (Lond) 2012; 26 (Suppl 2): S1S16.

[2] Cheung N, Mitchell P, Wong TY. Diabetic retinopathy. Lancet 2010; 376: 124-136.

[3] Hikichi T, Higuchi M, Matsushita T, Kosaka S, Matsushita R, Takami $\mathrm{K}$ et al. Two-year outcomes of intravitreal bevacizumab therapy for macular oedema secondary to branch retinal vein occlusion. Br J Ophthalmol 2014; 98 (2): 195-199.

[4] Jong Wook Lee, Hoon Park, Jeong Han Choi, Hyun Joo Lee, Sang Woong Moon, Ja Heon Kang, and Young Gyun Kim. Short-term changes of intraocular pressure and ocular perfusion pressure after intravitreal injection of bevacizumab or ranibizumabBMC Ophthalmol. 2016; 16: 69.

[5] Manousaridis K, Talks J. Macular ischaemia: a contraindication for anti-VEGF treatment in retinal vascular disease? Br J Ophthalmol. 2012; 96 (2): 179-184.

[6] Valentina Sarao, Daniele Veritti, Francesco Boscia, and Paolo Lanzetta. Intravitreal Steroids for the Treatment of Retinal Diseases. Scientific World Journal. 2014; 2014: 989501.

[7] K Kriechbaum, S Prager, G Mylonas, C Scholda, G Rainer, M Funk, M Kundi, U Schmidt-Erfurth, Intravitreal bevacizumab (Avastin) versus triamcinolone (Volon A) for treatment of diabetic macular edema: one year results. The Scientific Journal of the Royal College of Ophthalmologists. 2014 Jan; 28 (1): 9-16.

[8] Fung AE, Rosenfeld PJ, Reichel E. The Intrnational Intravitreal Bevacizumab Safety Survery: using the internet to assess drug safty worldwide. J Ophthalmol 2006, 90: 1344-9.

[9] Mason JO $3^{\text {rd }}$, Albert MA Jr, Vial R. Intravitreal bevacizumab (Avastin) for refractory pseudophakic cystoid macular edema.
Retina 2006, 26: 356-7.

[10] Bakri SJ, Snyder MR, Reid JM, Pulido JS, Singh RJ. Pharmacokinetics of intravitreal bevacizumab (Avastin). Ophthalmology 2007; 114 (5): 855-859.

[11] Gillies MC, Sutter FK, Simpson JM, Larsson J, Ali H, Zhu M. Intravitreal triamcinolone for refractory diabetic macular edema: Tow-year results of a double masked, placebocontrolled, randomized clinical trial. Ophthalmology 2006, 133: $1533-8$.

[12] McCuen BW2nd, Bessler M, Tano Y, Chandler D, Machemer R. The lack of toxicity of intravitreally administered triamcinolone acetonide. Am J Ophthalmol 1981, 91: 7858.

[13] Sampat KM, Garg SJ. Complications of intravitreal injections. Curr Opin Ophthalmol 2010; 21 (3): 178-183.

[14] George Kampougeris, Dimitrios Spyropoulos, and Adrianna Mitropoulou. Intraocular Pressure rise after Anti-VEGF Treatment: Prevalence, Possible Mechanisms and Correlations. Journal of Current Glaucoma Practice. 2013 Jan-Apr; 7 (1): 19-24.

[15] Aref AA: Management of immediate and sustained intraocular pressure rise associated with intravitreal antivascular endothelial growth factor injection therapy. Curr Opin Ophthalmol 2012; 23: 105-110.

[16] Weerawat Kiddee, Mayuree Montriwet. Intraocular Pressure Changes in Non-Glaucomatous Patients Receiving Intravitreal Anti-Vascular Endothelial Growth Factor Agents. Published: September 11, 2015.

[17] Michelson G, Groh MJ, Langhans M: Perfusion of the juxtapapillary retina and optic nerve head in acute ocular hypertension. Ger J Ophthalmol 1996; 5: 315-321.

[18] Pershing S, Bakri SJ, Moshfeghi DM. Ocular hypertension and intraocular pressure asymmetry after intravitreal injection of antivascular endothelial growth factor agents. Ophthalmic Surg Lasers Imaging Retina. 2013 Sep-Oct; 44 (5): 460-4. Doi: 10.3928/23258160-20130909-07.

[19] Sulman Jaffar, Ali Tayyab, Zeba I Matin, Amena Masrur, Rehan Naqaish. EFFECT OF INTRA VITREAL INJECTION OF BEVACIZUMAB ON INTRA-OCULAR PRESSURE. J Ayub Med Coll Abbottabad 2016; 28 (2): 360-3.

[20] Mehmet OZGUR CUBUK, Erkan UNSAL. Intraocular Pressure Changes in Eyes Treated with Intravitreal Injections of Anti-Vascular Endothelial Growth Factor for Age Related Macular Degeneration: The Results of Real Worlds. RetinaVitreus/Journal of Retina-Vitreous. 2019, Vol. 28 Issue 2, p165-170.6p.

[21] Behrooz Heydari, Saeed Reza Heydari, Gholamhossein Yaghoobi. Effect of Avastin on intraocular pressure before and after intravitreal injections. Journal of Surgery and Trauma 2016; 4 (3-4): 44-4.

[22] Yogish S. Kamath, Ashish Rander, Shailaja B S3, Lavanya G. Rao, Sulatha V Bhandary. The intraocular pressure changes following intravitrealbevacizumab injections in an Indian population. DOI: 10.18231/2395-1451.2018.0020.

[23] Ashiyana Nariani, Blake Williams, and Seenu M Hariprasad. Long-term effect of anti-vascular endothelial growth factor injections on intraocular pressure. Indian Journal of Ophthalmology. 2016 Sep, 64 (9): 643-647. 
[24] Mahmood Ali, Furqan Ahmad Khan, Sarah Zafar, Farah Akhtar. Short and long term intraocular pressure changes after intravitreal injections of triamcinolone acetonide and bevacizumab in diabetic macular edema. Rawal Medical Journal: Vol. 39. No. 4, Oct-Dec 2014.

[25] Sibel Aksoy, Gursel Yilmaz, Imren Akkoyun, and Ayse Canan Yazici Comparison of intravitreal bevacizumab and triamcinolone acetonide theraphies for diffuse diabetic macular edema. International Journal of Ophthalmology International Journal of Ophthalmology, 18 Jun 2015, 8 (3): $550-555$.

[26] Matthew Sniegowski, Naresh Mandava, and Malik Y Kahook. Sustained Intraocular Pressure Elevation After Intravitreal Injection of Bevacizumab and Ranibizumab Associate with Trabeculitis. Published online 2010 Jun 22. Doi: $10.2174 / 1874364101004010028$.

[27] Kahook MY, Liu L, Ruzycki P, et al. High-molecular-weight aggregates in repackaged bevacizumab. Retina. 2010; 30: 88789.

[28] Singh RS, Kim JE. Ocular hypertension following intravitreal anti-vascular endothelial growth factor agents. Drugs Aging. 2012; 29: 949-56. [PubMed] [Google Scholar].

[29] Ahmet taylan yazıcı C. Alagöz N. Alagöz et al. Intraocular pressure changes after different types of intravitreal injections for the treatment of macular edema. June 2011 - RetinaVitreus 19 (2): 117-12.

[30] Yong Woon Shin, MD, Hee Yoon Cho, MD, Yoon Jung Lee, MD, Min Chul Seong, MD. The Long-Term Observation of Intraocular Pressure after Intravitreal Injections of Bevacizumab, Triamcinolone, and Combination of Both. J Korean Ophthalmol Soc 2011; 52 (5): 574-581.

[31] Sameh Mohamed Elgouhary, Hatem Mohamed Marey, Hoda Mohamed Elsobky, Esraa Samy. Intraocular Bevacizumab,
Triamcinolone Acetonide or combination Treatment For Macular Edema Secondary to Branch Ritenal Vein Occlusion. INTRNATIONAL JOURNAL OF OPHTHALMIC RESEARCH 2015 June 1 (1): 24-27.

[32] Golakiya HN, Hirapara HN, Parmar SJ, Naik VN, Tripathi CB Triamcinolone Acetonide and Bevacizumab Induced Raised Intraocular Pressure in An Elderly Made Diabetic Patient - A Case Report. Curr Drug Saf. 2016, 11 (3): 270-1.

[33] Clark AF, Wilson K, McCartney MD, Miggans ST, Kunkle M, Howe W. Glucocorticoid-induced formation of cross-linked actin networks in cultured human trabecular meshwork cells. Invest Ophthalmpl vis. sci1994; 35 (1): 281-294.

[34] Sever Ozkan, Horozoglu Fatih, Celik Erkan, Topcu Birol. Intravitreal bevacizumab versus bevacizumab and $1 \mathrm{mg}$ triamcinolone acetonide in eyes with bilateral diabetic macular edema. Int Eye Sci, Vol. No 1, Jan. 2019.

[35] Valerie C. Lerebours; Jane S. Myung, MD; Jesse N. Cohen; Ben Z. Cohen, MD. Intraocular Pressure In Eyes Treated With Intravitreal Combination Of $1 \mathrm{mg}$ Triamcinolone Acetonide And $1.25 \mathrm{mg}$ Bevacizumab. Investigative Ophthalmology \& Visual Science March 2012, Vol. 53, 881.

[36] Tze-Yi Chan, Cheng-Kuo Cheng. Intraocular Pressure changes after repeated intravitreal anti vascular endothelial growth factor injections in paitents with or without glaucoma. Taiwan Journal of Ophthalmology, March 2014, 28-32.

[37] Falkenstein IA, Cheng L, Freeman WR. Changes of intraocular pressure after intravitreal injection of bevacizumab (avastin). Retina. 2007 Oct; 27 (8): 1044-7.

[38] Yandan Zhou, Minwen Zhou, Shigang Xia, Qiancheng Jing, and Ling Gao. Sustained Elevation of Intraocular Pressure Associated with Intravitreal Administration of Anti-vascular Endothelial Growth Factor: A Systematic Review and MetaAnalysis. SCIENTIFIC REPORTS. 2016; 6: 39301. 